area and tonnages, the need for improved diet is not neglected. On account of the great distances, a general transfer of food from 'surplus' to 'deficit' provinces is impracticable. The solution is, in the author's view, a great increase in irrigation; but in Bombay it is not possible to extend greatly the kind of barrage-and-canal irrigation that has been a spectacular success in the river-plains regions. The pamphlet may be regarded as a reasoned critique of canal irrigation. Contour cultivation (bunding) may increase yields in hilly areas, but the crops suitable for upland cultivation are grains of low nutritional value, of which Bombay normally has a surplus ; and contouring is incompatible with storage from catchments. The ultimate solution for Bombay Province, therefore, is a very great increase in the number of small wells. The author suggests how these might be planned and financed, and in addition he shows how barrage and water-storage schemes could be provided so as to make the greatest possible use of all water resources. The pamphlet is stimulating, and has much value as a source of information regarding the current status and economics of irrigation and foodproduction in various provinces of India. The reader is left with the feeling that the main difficulty is social rather than engineering.

Horticultural Uses of D.D.T.

A USEFUL short paper by G. Fox Wilson ( $J$. Roy. Hort. Soc., 71, Pt. 1, January 1946) gives some timely results with the use of D.D.T. for controlling various garden pests. This substance has no egg-killing properties, is useless against red spider and other acarine mites, and has no useful action against aphids. Spectacular control of numerous pests is reported, however, notably of the apple blossom weevil and of the greenhouse thrips (Heliothrips hoemorrhoidalis). The unselective action of D.D.T. can be a danger, for ladybirds and other predators are killed along with the pests. Use of the substance as a larvicide in garden ponds may be a very mixed blessing for other and more desirable members of the fauna. Hive bees and other pollinating insects are destroyed by untimely applications. It is very obvious that D.D.T. must be used with care, and under expert advice, until its wide implications are thoroughly investigated.

\section{Arsenic in Tobacco Smoke}

THE presence of arsenic in the smoke of some kinds of tobrceo is the subject of an annotation in the British Medical Journal (94, Jan. 19, 1946). Reming. ton (J. Amer. Chem. Soc., 49, 1410; 1927) found that about half the arsenic present is volatilized when tobacco is smoked, and Gross and Nelson (Amer. J. Pub. Health, 24, 36 ; 1934) showed that $15-40$ per cent of it goes into the smoke. Thomas and Collier (J.Indust. Hyg., 27, 201 ; 1945) found wide variations in the arsenic content of different brands of tobacco. In the puffed smoke of the cigars used for their experiments they found $0 \cdot 2-3 \cdot 0 \mathrm{mgm}$. of arsenious oxide, in that of the pipe tobacco examined 1.7$5.7 \mathrm{mgm}$., and in that of the cigarettes 3.3-10.5 mgm. The cigars themselves, however, contained less arsenic than the pipe tobacco or cigarettes. H.M. Chief Inspector of Factories, continues the annotation, in his annual report for 1943 (Cmd. 6563, H.M. Stationery Office, 1944) recorded three cases of carcinoma of the lung since 1939 in arsenical sheepdip workers and referred to the high incidence of this disease in arsenic workers, a problem which is being studied by the Medical Research Council. There appears to be strong evidence that arsenic dust predisposes to carcinoma of the respiratory tract. The carcinogenic properties of the arsenic in tobacco smoke and the enormous increase in the use of tobacco justify, it is stated, a full investigation of this subject.

\section{Centenary of F. W. Bessel (I784-1846)}

Friedrich Wilhelm Bessei, the great German astronomer, was born on July 22, 1784, at Minden, about thirty miles east of Hanover. An aptitude for figures and a distaste for Latin led to his apprentice. ship in his fifteenth year to a mercantile house in Bremen. Here he acquired a knowledge of English and Spanish, studied geography and navigation, and from these subjects he "groped his way into a new world of astronomy and mathematics". The works of Bode, von Zach and Lalande were his companions, and by their aid he deduced an orbit for Halley's Comet. The result he sent to Olbers, who immediately sent it to von Zach for publication, and thus Bessel's name became known. In 1805, Harding, Schröter's assistant at Lilienthal, was transferred to Göttingen, and Bessel, whose success in business was assured, renounced the prospect of comparative affluence for "poverty and the stars". Five years later he was chosen by the Prussian Government to superintend the erection of the new observatory at Königsberg, on the completion of which he was appointed director. Through his labours this establishment became the chief of German observatories and a centre of improvement for the whole astronomical world. Bessel remained at Königsberg for the rest of his life and died there on March 17, 1846.

Bessel's first great work appeared in 1818 under the title of "Fundamenta Astronomiæ". In this he gave to the world the results of his elaborate investigations of Bradley's observations made at Greenwich during 1750-62. "The eminent value of the work consisted in this, that by providing a mass of entirely reliable information as to the state of the heavens at the epoch 1755, it threw back the beginning of exact astronomy almost half a century" (Clerke). In 1830 Bessel published his "Tabulæ Regiomontanæ", which became the standard work of its kind. He had, in 1821, commenced observations of all stars down to the ninth magnitude comprehended within the parallels of $15^{\circ}$ south declination and $45^{\circ}$ north declination. In this he was assisted by Argelander. The observations amounted to 75,000 and they were not complete until 1833 . He also determined the parallax of $\gamma$ Cygni, he made many observations and physical inquiries on comets, he investigated the theory of the pendulum, discussed the figure of the earth, and also directed the operations for connecting the Russian triangulation with those of Western Europe. His name is also associated with the Bessel function; this mathematical form, developed by Bessel for research in planetary perturbations (1824), has been widely used in celestial mechanics, wave-theory, elasticity, hydrodynamics and related modern investigations.

\section{Giulio Bizzszero (I846-1901)}

Tнобан the memory of Bizzozero, the centenary of whose birth falls on March 20, is eponymously honoured in 'Bizzozero's corpuscles', it may be said without undue straining of the phrase that his signature is writ large upon many a page in the annals of 